\title{
EDITAIS DE CONCURSOS PÚBLICOS: ANÁLISE DAS ATRIBUIÇÕES DOS INTÉRPRETES EDUCACIONAIS LIBRAS-PORTUGUÊS
}

\author{
CIVIL SERVICE EXAMINATION NOTICES: AN ANALYSIS OF DUTIES ASSIGNED \\ TO BRAZILIAN SIGN LANGUAGE-PORTUGUESE INTERPRETERS IN THE AREA OF \\ EDUCATION
}

\begin{abstract}
CONVOCATORIAS DE OPOSICIONES PÚBLICAS: ANÁLISIS DE LAS ATRIBUCIONES DE LOS INTÉRPRETES EDUCATIVOS DE LENGUA DE SIGNOS BRASILEÑA/PORTUGUÉS
\end{abstract}

\author{
Camila Francisco * \\ Silvana Aguiar dos Santos **
}

\begin{abstract}
Resumo
No Brasil, uma série de políticas linguísticas em torno da Língua Brasileira de Sinais foram implementadas com maior vigor a partir do Decreto $n^{\circ} 5.626 / 05$. Mesmo com os avanços das políticas linguísticas, há vários desafios quanto à contratação de tradutores e intérpretes de língua de sinais (TILS), principalmente, no contexto educacional. Esta pesquisa investiga as atribuições que deverão ser desempenhadas pelos profissionais nas cidades de Florianópolis e Itajaí, no contexto educacional da educação básica. O corpus utilizado nesta pesquisa restringiu-se aos editais de concursos públicos publicados nos anos de 2005 a 2013 . No contexto educacional, aspectos como processos de aprendizagem dos alunos surdos, confusão de papéis entre a docência e o exercício tradutório são fatos que perpassam a atuação desses profissionais. Esta pesquisa tem o intuito de observar, analisar e classificar as atribuições presentes nos editais destinadas aos TILS nas cidades analisadas. A metodologia adotada é a análise documental, bibliográfica de cunho qualitativo. Os dados revelam que a cidade de Itajaí tem mais atribuições de cunho tradutório do que a cidade de Florianópolis. Constatamos ainda a necessidade de diretrizes sobre o exercício tradutório no contexto educacional, com respaldo nos preceitos da interpretação comunitária.
\end{abstract}

Palavras-chave: intérprete educacional, Libras-Português, atribuições de trabalho.

\footnotetext{
* Bacharel em Letras Libras pela Universidade Federal de Santa Catarina - UFSC.

E-mail: camilallufsc@gmail.com

**Doutora em Estudos da Tradução e Mestre em Educação pela Universidade Federal de Santa Catarina- UFSC. Professora Adjunta no curso de Letras - Libras do Departamento de Artes e Libras. E-mail: aguiar.sil@gmail.com
} 
Novos espaços de atuação profissional para tradutores e intérpretes de língua de sinais (doravante TILS) emergiram, de forma considerável, a partir da Lei de Libras n 10.436/2002. Exemplos disso são os contextos midiático/televisivo, por telefone/streaming, médico, jurídico e educacional, entre outros. Ainda assim, o contexto educacional é o que mais se destaca, tanto do ponto de vista acadêmico, dadas as várias pesquisas realizadas, bem como pelas inúmeras oportunidades de trabalho.

Embora o contexto educacional esteja avançando e os TILS tenham alcançado significativas conquistas, seja por meio de formação acadêmica, ou políticas linguísticas em torno da língua brasileira de sinais, a Libras, há vários desafios a serem considerados. Um exemplo disso ocorre quando nos deparamos com as formas de contratação de TILS, pois se percebe que estamos distantes de uma política de contratação e atuação do que se pode considerar adequado ao contexto educacional e que qualifique o serviço oferecido nesse campo.

O contexto educacional tem se tornado visível na tradução e interpretação de Libras, entretanto, há inúmeros caminhos a percorrer, para que os TILS tenham melhores condições de trabalho, como: o intervalo de revezamento, a contratação de profissionais qualificados com formação específica e diretrizes efetivas das atribuições profissionais etc. Esses elementos podem contribuir para a melhor atuação em sala de aula do profissional TILS e, consequentemente, para a excelência da educação de surdos em escolas inclusivas.

Nesta pesquisa, utilizamos os referenciais teóricos dos Estudos da Tradução, mais especificamente, o conceito de interpretação comunitária, para problematizar o contexto educacional. Com relação ao objetivo geral, analisamos as atribuições dos editais de concursos públicos para TILS nos municípios de Florianópolis e Itajaí, ambos do Estado de Santa Catarina, no período de 2005 a 2013. Utilizamos a abordagem de cunho qualitativo e, como instrumento, metodologias (documental e bibliográfica) que focam o aspecto cronológico dos fatos. Os documentos selecionados são editais de concurso público, de caráter efetivo, da carreira de magistério. Dessa forma, analisamos as atribuições desses editais, descartando as análises de provas objetivas, provas de títulos e provas práticas.

As perguntas que impulsionaram esta pesquisa foram: Quais as mudanças e as implicações das atribuições de TILS nos editais de concursos públicos no período de 2005 a 2013 nas cidades de Florianópolis e Itajaí? Quais as semelhanças e diferenças registradas nos 
editais para TILS dessas duas cidades? Em seguida, na análise dos dados, expomos os resultados obtidos nesta pesquisa, discutindo como essas atribuições implicam em posturas e práticas de TILS no cotidiano escolar. Por fim, expomos algumas considerações finais.

\section{Contextos de interpretação}

Há distintos contextos de interpretação como: congressos, eventos internacionais, consultas médicas, atendimento no Ministério Público, ambientes escolares, desde a educação infantil até o ensino superior, incluindo pós-graduação. Essa grande esfera da interpretação é dividida em duas seções: interpretação comunitária e interpretação de conferências. Para definir "interpretação comunitária", respaldamo-nos em Shuttleworth e Cowie (1997), para quem essa forma de interpretação tem como objetivo proporcionar aos falantes de uma língua minoritária o acesso aos serviços públicos da comunidade onde vivem.

Pöchhacher (2004), Wadensjö (2004), Rodrigues (2010) e Queiroz (2011) são alguns dos autores que tratam sobre temáticas que envolvem o contexto comunitário. Por exemplo, Rodrigues (2010) realiza uma distinção entre os conceitos de interpretação de conferência e interpretação comunitária. O autor apresenta algumas características desse contexto comunitário, entre elas:

[...] atividade de caráter intrassocial; atividade ligada às instituições públicas e ao acesso aos bens públicos; interpretação consecutiva/intermitente de interações reais e diálogos espontâneos, face a face, e não de discurso; interpretação de e para ambas as línguas, sendo uma delas a língua oficial do país e outra de minoria, comunidade estrangeira ou outro grupo marginalizado (RODRIGUES, 2010, p. 5).

Nessa perspectiva, entendemos que os itens relacionados acima se aplicam ao cotidiano dos TILS que atuam em sala de aula e, por essa razão, temos fortes elementos que conectam o contexto educacional como pertencente à área de interpretação comunitária, envolvendo o par linguístico formado por Libras e Português. Trata-se de algo frequente, pois essas línguas ocupam o mesmo espaço geográfico. Entretanto, o índice de pessoas bilíngues nesse par linguístico ainda é reduzido, o que gera demandas de interpretação, em diversas áreas.

Os contextos em que o intérprete é mais solicitado, e nos quais a sua presença é assegurada pelo Decreto $\mathrm{n}^{\circ} 5.626 / 05$, são: o educacional, em que é garantido ao aluno o ensino na sua primeira língua (Libras) e a presença de TILS, professores de Libras ou 
instrutor de Libras. Além desses, estão os contextos médico e jurídico. Todos, segundo o decreto em questão, exigem que profissionais da área sinalizem ou que haja a presença de TILS. Será sob essa perspectiva conceitual que trataremos, na próxima seção, o contexto educacional, dialogando com alguns desafios registrados na literatura da área.

O contexto educacional é um dos mais requisitados na interpretação. Além de um farto campo de trabalho, há diversas pesquisas na área como: Dorziat e Araújo (2012), Camargo e Albres (2011), Quadros (2004), dentre outros autores. Quadros (2003) faz um apanhado geral da profissão do TILS, especificando em um capítulo as complexidades de atribuir funções para TILS educacionais:

O intérprete especialista para atuar na área da educação deverá ter um perfil para intermediar as relações entre os professores e os alunos, bem como, entre os colegas surdos e os colegas ouvintes. No entanto, as competências e responsabilidades desses profissionais não são tão fáceis de serem determinadas (QUADROS, 2004, p. 59).

É necessário tratar das atribuições desses profissionais, pois, em nosso ver, há grandes discussões no âmbito do ensino superior e poucas abordagens no que diz respeito à educação básica. É comum observarmos na literatura da área que, ao discutir as atribuições ou responsabilidades do TILS, as expectativas são de que esses profissionais tenham formação ou desenvolvam atividades para além das questões tradutórias. Por exemplo, Dorziat e Araújo (2012) afirmam que o TILS educacional deve ter formação que esteja além da fluência linguística, bem como formação no campo educacional.

Por outro lado, Camargo e Albres (2011) analisam as formas de contratação dos TILS educacionais por meio de levantamento dos conhecimentos exigidos nas provas de concursos. Os resultados dessa pesquisa constatam que, na maioria das vezes, as provas objetivas são superficiais, dando margem para que candidatos que não estejam aptos para a atuação sejam aprovados. Considerando essas divergências e a falta de efetividade na formação, nas provas de seleção e nas atribuições, Costa, Ebling e Witchs (2012) investigaram sobre as funções desempenhadas pelos TILS educacionais e encontraram distintas funções em sua atuação.

Essas funções foram divididas em quatro categorias: (1) TILS, aquele que exerce a função de interpretar; (2) professor particular, profissional encarregado de ensinar o aluno Surdo; (3) cuidador, aquele que interage com o aluno Surdo enquanto a aula é ministrada para os demais alunos e não interpreta, ficando o professor regular em segundo plano; (4) categoria não estabelecida, pois o profissional estudado declarou não saber sua função. É notória a 
complexidade identitária dos TILS que atuam no campo educacional, crise essa possivelmente agravada pela falta de diretrizes efetivas, e que estejam respaldadas na interface Estudos da Tradução e Educação. Nesse sentido, desenvolvemos na próxima seção os aspectos metodológicos que nortearam esta pesquisa.

\section{Aspectos metodológicos}

Trataremos os dados com dois procedimentos: o documental e o bibliográfico. Pesquisas que focam em procedimentos documentais nos permitem analisar as transformações sociais num dado período de tempo e perceber, por meio dos documentos, seus avanços ou não com o passar dos anos. A desvantagem de analisar os editais é o fato de não saber se realmente os profissionais atuam de acordo com o que esses documentos estabelecem. E essa é uma temática para futuras pesquisas. Com relação aos procedimentos de cunho bibliográfico, esses estão presentes em todas as pesquisas, mesmo que não sejam mencionados, pois se faz necessário o levantamento bibliográfico para que o pesquisador fundamente seu texto, teoricamente, na literatura do seu campo de estudo.

Em termos gerais, os estudos qualitativos envolvem a coleta de dados utilizando de técnicas que não pretendem medir nem associar as medições a números, tais como observação não estruturada, entrevistas abertas, revisão de documentos, discussão em grupo, avaliação de experiências pessoais, inspeção de histórias de vida, análise semântica e de discursos cotidianos, interação com grupos ou comunidades e introspecção. (SAMPIERI; COLADO; LUCIO, 2012, p. 10, grifos do autor).

Ou seja, os editais são importantes fontes de coleta de dados, constituindo o primeiro passo da pesquisa. A escolha por analisar documentos de concursos públicos partiu do pressuposto de que esses trariam subsídios para as discussões acerca das atribuições dos TILS, tendo em vista sua diversidade de atuação, como apresentam Costa, Ebling e Witchs (2012). Além disso, como os editais são documentos normativos, responsáveis por orientar o profissional, podem ser explorados em pesquisas.

Como recorte de tempo, escolheu-se o período entre 2005 a 2013. O ano de 2005 foi escolhido como recorte inicial em decorrência da publicação do decreto $\mathrm{n}^{\circ} 5.626 / 05$, tendo a expectativa de mudanças nas contratações de TILS a partir dessa data. Cabe ressaltar que o referido decreto apresenta encaminhamentos sobre a formação desses profissionais e sugere 
implementações no âmbito municipal, estadual e federal. O ano de 2013 foi escolhido como recorte final, uma vez que havia necessidade de tempo hábil para realizar as análises.

As cidades selecionadas foram Florianópolis e Itajaí, ambas do Estado de Santa Catarina. A cidade de Florianópolis foi selecionada por ser sede do curso de graduação presencial de Bacharelado em Letras-Libras, cujo objetivo é formar Tradutores/intérpretes de Libras. A cidade de Itajaí, por contar com o Serviço de Atendimento à Pessoa Surda (SAPS), na Universidade do Vale de Itajaí (Univali), que é uma referência no ensino de Libras para crianças surdas, seus familiares e a comunidade.

Após o levantamento dos editais de concurso público, passamos para a triagem dos cargos, verificando quais editais continham o cargo de TILS. A partir desse recorte, focalizamos o objeto de estudo: os editais que contêm o cargo de TILS, 001-2009, 008-2010 e 003-2011 de Florianópolis, e 004-2011 e 022-2013, da cidade de Itajaí. O passo seguinte foi a análise das categorias: nomenclatura do cargo, formação e atribuições de cunho tradutório, pedagógico e de cunho ambíguo. Articulamos os resultados obtidos nas análises, em consonância com as literaturas sobre interpretação educacional e Estudos da Tradução.

\section{Atribuições de TILS no contexto educacional segundo os editais}

A primeira diferença entre os editais, no que se refere aos TILS, é a nomenclatura do cargo. Na primeira cidade, Florianópolis, o cargo é "Auxiliar de ensino de Libras (Língua Brasileira de Sinais)" e na cidade de Itajaí é de "Intérprete de Língua Brasileira de Sinais". Apesar de a definição do cargo no edital da segunda cidade ser de Intérprete de Língua Brasileira de Sinais, não há garantia de que a formação mínima exigida possa ser na área de tradução e interpretação, nem ao menos de que as atribuições não estejam ligadas à carreira de docência. Itajaí destaca-se, quando comparada com Florianópolis, pois "auxiliar de ensino" pode trazer dúvidas ao TILS, quanto ao real significado da expressão. É fundamental que os gestores, TILS e demais interessados, analisem as implicações semânticas e políticas que estão contidas nas palavras. Um exemplo disso é a expressão "auxiliar de ensino", que acarreta atribuições distintas, sugerindo às escolas que o TILS educacional tenha responsabilidades com o ensino-aprendizagem do educando Surdo.

A distinção dessas nomenclaturas respalda-se nas leis de cargos dos municípios, visto que a cidade de Itajaí tem um cargo específico para TILS, dispondo de formação, atribuições e plano de carreira. Já a cidade de Florianópolis criou um cargo mais abrangente, "professor 
auxiliar de ensino de Libras". Nos editais são especificadas as áreas de atuação de cada professor auxiliar, assim como suas atribuições. A lei de cargos especifica apenas a necessidade de o profissional ser licenciado. Outra ressalva refere-se à língua portuguesa, que não é mencionada no edital. Dessa forma o profissional é referenciado somente como intérprete de Libras. Cabe destacar que o par linguístico de atuação no contexto educacional brasileiro é Libras-Português, e isto deveria estar especificado na nomenclatura do cargo.

Outra diferença registrada entre as duas cidades foi quanto à formação. Os editais da cidade de Florianópolis exigem formação em docência para o cargo de Auxiliar de Ensino de Língua Brasileira de Sinais- Libras, sem exigir formação específica, salientando-se apenas que é necessário ser na área da educação. Quanto ao domínio da língua, o edital não explicita como será comprovada essa competência. Como umas das etapas do concurso é a prova prática, a banca deve responsabilizar-se por avaliar o domínio em Libras dos candidatos.

Nos editais da cidade de Itajaí, para o cargo "Intérprete de Língua Brasileira de Sinais" a formação mínima exigida é: "Superior Completo em Pedagogia e curso específico certificado pela FENEIS (Federação Nacional de Educação e Integração dos Surdos) ou por órgão nacional regulador da profissão". É válido salientar que a formação em Pedagogia habilita o profissional a lecionar até o quinto ano do ensino fundamental. Ainda mais importante é lembrar que a Lei de Diretrizes e Bases da Educação Nacional (LDB) prevê como responsabilidade dos municípios a educação básica, até o nono ano. Na ausência do ensino médio na rede estadual, esse nível de ensino poderá ficar a cargo das escolas municipais.

Sabendo-se que o TILS não escolhe o ano/série em que irá trabalhar, poderá atuar em ano/série a que o curso de Pedagogia não o habilita. O curso da FENEIS atualmente é ofertado somente em São Paulo, e a certificação de proficiência, desde o Decreto n ${ }^{\circ}$ 5.626/05, é expedida pelo Prolibras, não sendo a FENEIS responsável por esse exame. E, ainda, na Lei $n^{\circ} 12.319 / 10$, especifica-se, no artigo $4^{\circ}$, que a formação do TILS deve ser em nível médio, com formação continuada em cursos profissionalizantes e curso de extensão universitária, os quais, como podemos constatar, não são competências exigidas nos editais.

Assim como a terminologia utilizada na descrição do cargo na cidade de Florianópolis está relacionada à prática de docência, a formação mínima exigida relaciona-se ao ensino, contrariando a lei que regulamenta a profissão de TILS. Os editais, ao longo dos anos, 
reproduziram as mesmas atribuições, ou seja, não ocorreram mudanças nos editais de Florianópolis e Itajaí no período de 2005 a 2013.

Apesar de os concursos serem publicados com curto intervalo de tempo, em ambas as cidades, não encontramos modificações, mantendo-se com as mesmas atribuições, o que implica em não haver discussões acerca de tais atribuições nas instituições e na gestão pública, que criam esses editais. Percebe-se, então, a necessidade de problematizar a ideia de que os TILS são responsáveis pela aprendizagem do educando Surdo, bem como, de que os TILS não necessitam de formação em nível superior na área de tradução/interpretação, uma vez que outras áreas são solicitadas em editais.

Por fim, com relação às atribuições, temos os seguintes resultados distribuídos nos quadros a seguir. Na categoria de cunho tradutório, reunimos atribuições que têm caráter tradutório e interpretativo, como estratégias de tradução/interpretação, estudo prévio, entre outras, em função das quais o profissional TILS necessita desenvolver suas competências linguísticas, referenciais, tradutórias e culturais. As informações transcritas vieram de dados da pesquisa.

Quadro I - Atribuições de cunho tradutório

\begin{tabular}{|c|c|}
\hline $\begin{array}{l}\text { Florianópolis: } \\
\text { 001-2009, 008-2010 } \\
\text { e 003-2011 }\end{array}$ & $\begin{array}{l}\text { Itajaí: } \\
\text { 004-2011 e 022-2013 }\end{array}$ \\
\hline $\begin{array}{l}\text { (a) Caberá a tradução } \\
\text { e interpretação da } \\
\text { Língua Brasileira de } \\
\text { Sinais para o } \\
\text { Português e vice- } \\
\text { versa em quaisquer } \\
\text { modalidades que se } \\
\text { apresentar (oral ou } \\
\text { escrita). }\end{array}$ & $\begin{array}{l}\text { (1) Facilitar e mediar a comunicação entre surdos e ouvintes, realizando a tradução } \\
\text { da língua brasileira de sinais e da língua portuguesa para a pessoa surda, traduzindo } \\
\text { falas, diálogos, palestras, explanações orais, reuniões, entre outros; } \\
\text { (2) Atuar em salas de aula e em eventos ligados ao ensino, para realizar a } \\
\text { interpretação por meio da língua de sinais; } \\
\text { (3) Coletar informações sobre o conteúdo a ser trabalhado para facilitar a tradução da } \\
\text { língua no momento das aulas e atividades escolares; } \\
\text { (4) Planejar antecipadamente, junto com o professor responsável pela disciplina ou } \\
\text { série, sua atuação e limites no trabalho a ser executado; } \\
\text { (5) Participar de atividades extraclasse, como palestras, cursos, jogos, encontros, } \\
\text { debates e visitas, junto com a turma em que exercite a atividade como intérprete; } \\
\text { (6) Manter contato com a comunidade surda e a cultura dos surdos, bem como } \\
\text { participar de formações e cursos de atualização e aperfeiçoamento e das atividades e } \\
\text { avaliações exigidas pelo órgão nacional regulador da categoria; } \\
\text { (7) Executar outras atribuições, correlatas às acima descritas, conforme demanda e/ou } \\
\text { a critério de seu superior imediato. }\end{array}$ \\
\hline
\end{tabular}

Fonte: FLORIANÓPOLIS, 2009, 2010, 2011; ITAJAÍ, 2011, 2013 
As atribuições não são semelhantes no léxico, mas sim no sentido, sendo a segunda coluna mais detalhada que a primeira. Em Florianópolis, considera-se a tradução e a interpretação como modalidades distintas que exigem competências diferentes. Em Itajaí, o início da primeira frase: "Facilitar e mediar a comunicação entre surdos e ouvintes" indica uma atividade que qualquer profissional bilíngue no par Libras-Português poderia fazer. Ainda que o texto dê continuidade à frase e associe a tradução em um segundo momento como parte das atribuições do candidato, a descrição é problemática. Isso ocorre porque a tarefa de interpretar ou traduzir não é priorizada como primeira atribuição. Nem todo bilíngue apresenta as competências necessárias para traduzir, conforme Albir (2005). Outro ponto constatado em Itajaí foi que a tradução deve ser direcionada para a pessoa Surda. Contudo, tanto a tradução quanto a interpretação são vias de mão dupla, ora para a pessoa Surda, ora para a pessoa ouvinte.

Todas essas atribuições descritas e analisadas mantêm uma semelhança em relação às atividades a serem executadas. As demais atribuições, que serão descritas a partir deste momento, são diferentes nas duas cidades. Constatamos que Itajaí é constituída por atribuições que se relacionam diretamente com a área de tradução/interpretação, como veremos adiante. Nesse sentido, uma das maiores diferenças entre as cidades é, justamente, a priorização que uma dá ao ato tradutório e, a outra, à docência.

O contato com o professor regente em sala de aula é de suma importância, conforme a atribuição número 4, da cidade de Itajaí, pois o profissional TILS precisa gerenciar uma série de tarefas de alta complexidade. Essas tarefas colocam em cena a necessidade de analisar, discutir e repensar os perfis profissionais que são exigidos nos contextos educacionais. Realizar um mapeamento dessas demandas torna-se urgente, pois implica na formação desses TILS. Conforme aponta Quadros (2004), há necessidade de intérpretes especializados para atuar no campo educacional.

O intérprete especialista para atuar na área da educação deverá ter um perfil para intermediar as relações entre os professores e os alunos, bem como, entre os colegas surdos e os colegas ouvintes. No entanto, as competências e responsabilidades destes profissionais não são tão fáceis de serem determinadas (QUADROS, 2004, p. 59).

$\mathrm{Na}$ maioria das ocasiões os professores regentes não têm conhecimento sobre tradução/interpretação em contextos comunitários, como o contexto educacional. Por 
exemplo, se o professor pretender fazer um ditado ortográfico como atividade didática, talvez ele tenha consciência de que na ausência de alguns sinais, uma das estratégias de interpretação seria a datilologia. Essa estratégia, no entanto, invalidaria a atividade, pois a intérprete iria sinalizar letra por letra. O TILS, em parceria com o professor, poderia buscar outras formas de adaptação dessa atividade, corroborando a necessidade de uma parceria entre esses dois profissionais. Lacerda (2013) ratifica a importância do planejamento em conjunto como uma atividade que produz efeitos satisfatórios para ambos os profissionais. Acrescentamos ainda que tanto nos elementos didáticos quanto nos tradutórios, o nível de qualidade das aulas e das traduções tende a melhorar.

Nessa perspectiva, a atribuição de número 5, em Itajaí, novamente contextualiza possíveis locais de atuação, dessa vez priorizando atividade extraclasse. Ou seja, essa atribuição confirma que o espaço escolar pertence ao contexto comunitário, conforme tratado por Pöchhacker (2004). Na escola há demandas de interpretação que extrapolam o espaço da sala de aula, mas que, ainda assim, constituem espaços que se correlacionam ao ambiente escolar. Esses espaços colocam em jogo diferentes competências, as quais, se pensadas no âmbito da interpretação comunitária, podem ter ampliadas formas e estratégias de operacionalizar tarefas nesses espaços.

No Quadro II, agrupamos as atribuições de caráter pedagógico, isto é, aquelas que se relacionavam com as tarefas de ensinar e se responsabilizar pela aprendizagem do educando Surdo, entre outras.

Quadro II - Atribuições de cunho pedagógico

\begin{tabular}{|l|l|}
\hline Florianópolis 001-2009, 008-2010 e 003-2011 & Itajaí 004-2011 e 022-2013 \\
\hline $\begin{array}{l}\text { (b) comprometer-se com práticas educativas / } \\
\text { pedagógicas que atendam às demandas surgidas } \\
\text { no cotidiano da unidade educativa [...] }\end{array}$ & $\begin{array}{l}\text { As atribuições dispostas nos editais não se encaixam nessa } \\
\text { categoria. }\end{array}$ \\
$\begin{array}{l}\text { (d) comprometer-se com a aprendizagem das } \\
\text { crianças e adolescentes. }\end{array}$ & \\
\hline
\end{tabular}

Fonte: FLORIANÓPOLIS, 2009, 2010, 2011; ITAJAÍ, 2011, 2013

Ainda que não estejamos realizando uma análise lexical, constata-se, pela escolha do verbo "comprometer-se", que a prioridade de atuação para o TILS, nesse contexto, refere-se às questões pedagógicas, não havendo um lugar estabelecido para a tradução ou interpretação. Em suas pesquisas, Lacerda (2013) comenta as atribuições (b) e (d) dessa categoria, presentes 
no edital de Florianópolis, ao afirmar que: “[...] o papel de educador/professor não pode recair sobre o intérprete, já que seu papel principal é interpretar. O intérprete não pode ser responsabilizado pela aquisição de conhecimentos do aluno.” (LACERDA, 2013, p. 127). Apesar de o texto do edital apontar: "auxiliar de ensino de Libras" e se exigir a formação em licenciatura no edital de Florianópolis, tais encaminhamentos não são as diretrizes preconizadas pelo Decreto $\mathrm{n}^{\circ} 5.626 / 05$ e a Lei $\mathrm{n}^{\circ} 12.319 / 10$. Ambos os documentos atribuem aos TILS funções de tradução/interpretação.

Por fim, na categoria que denominamos "ambígua", elencamos as atribuições que não estão explícitas, mas que ficam ao encargo do leitor interpretar e compreender se são de cunho tradutório ou de cunho pedagógico.

Quadro III - Atribuições de cunho ambíguo

\begin{tabular}{|l|l|}
\hline Florianópolis 001-2009, 008-2010 e 003-2011 & Itajaí 004-2011 e 022-2013 \\
\hline $\begin{array}{l}\text { (c) seguir o proposto pela Unidade Educativa e seu } \\
\text { respectivo calendário [...] }\end{array}$ & $\begin{array}{l}\text { (7) Executar e acompanhar projetos educacionais } \\
\text { voltados à educação inclusiva. }\end{array}$ \\
$\begin{array}{l}\text { (e) desenvolver atividades de acordo com a } \\
\text { organização da Unidade Educativa e as diretrizes } \\
\text { curriculares em vigor. }\end{array}$ & \\
\hline
\end{tabular}

Fonte: FLORIANÓPOLIS, 2009, 2010, 2011; ITAJAÍ, 2011, 2013

Em Florianópolis, em ambas as atribuições, (c) e (e), não ficam bem determinadas as funções dos TILS na Unidade Educativa e nem as atividades que ali serão propostas, embora as atribuições devessem estar claras no edital, para que fossem evitados equívocos sobre as funções desempenhadas pelos TILS. É sabido que há diferentes funções dos TILS em sala de aula, conforme os resultados de Costa, Ebling e Witchs (2012), já mencionados anteriormente. No entanto, ressaltamos que, mesmo não havendo clareza quanto às tarefas que deverão ser executadas, essas propiciam oportunidades de incluir projetos que estejam voltados à tradução ou interpretação, no caso da atribuição (7) da cidade de Itajaí.

Muitas são as possibilidades de trabalho e pesquisa, respaldadas nas demandas da educação inclusiva. Os Estudos da Tradução e Estudos da Interpretação oferecem diretrizes para implementação desses serviços e há profissionais que podem ser formados para atuações dessa ordem, ainda que autores como Mourão, Dias Júnior e Cordeiro (2012) afirmem sobre a falta de definição das funções de TILS no contexto educacional. Rotinas também podem ser construídas e visibilizadas pela colaboração dos TILS, envolvidos em projetos junto a 
entidades parceiras na área de tradução ou associações da categoria. Enfim, os fatos constatados nessa pesquisa apontam para a necessidade de construção de um lugar para a tradução e interpretação de Libras-Português, respaldada na interpretação comunitária, no meio educacional.

\section{Considerações finais}

Ao longo desta pesquisa, analisamos os editais de concursos públicos de contratação efetiva, dos municípios de Florianópolis e Itajaí no período de 2005 a 2013. Um dos primeiros resultados observados foi a não ocorrência de qualquer mudança nas atribuições no período estudado. Constatamos que a cidade de Itajaí tem atribuições mais compatíveis com as competências de tradução ou interpretação do profissional TILS. Essas orientações estão fortemente atreladas ao contexto educacional, de acordo com documentos mencionados, como o Decreto ${ }^{\circ} 5.626 / 05$ e a Lei ${ }^{\circ} 12.319 / 10$.

Em Florianópolis, as atribuições estão entrelaçadas com a carreira de docência e, como observado ao longo deste trabalho, o TILS não deve ser responsabilizado pela aprendizagem do educando Surdo. Entre as duas cidades, essa é a principal diferença entre os editais estudados. Florianópolis caminha para a prática docente e Itajaí para a prática tradutória. A formação em docência foi validada nos editais pesquisados, com diferentes formações exigidas, mas com habilitação em licenciatura. Em Florianópolis, o nome do cargo também caminha para a atuação como docente e não como TILS, fato esse que precisa ser repensado sob os aspectos acadêmico-científico e político.

O momento atual é de repensar, problematizar e analisar as melhores formas de encaminhamento. Seja por reivindicações da categoria, por meio das associações estaduais e nacionais de tradutores/intérpretes de língua de sinais, ou por meio das pesquisas acadêmicas desenvolvidas. No ensino superior federal há uma luta efetiva dos TILS para que a exigência das vagas destinadas a esses profissionais seja de nível superior. Entendemos que essa reivindicação pode se ramificar, também, para o contexto educacional da educação básica. Mas nem tudo são posicionamentos negativos, pois percebemos mudanças sendo encaminhadas. Embora não tenha feito parte do escopo de análise, por ser contrato seletivo temporário, o edital emergencial da prefeitura municipal de Florianópolis, publicado no início de 2014, para preencher as vagas remanescentes, preconizava para o cargo TILS: 
Professor Auxiliar de Língua Brasileira de Sinais - Intérprete de LIBRAS (03 vagas): Formação no ensino médio em Magistério ou Graduado ou estudante da $5^{\text {a }}$ fase em diante dos cursos de Licenciaturas, ouvinte, com formação de tradutor e intérprete em Língua Brasileira de Sinais. (FLORIANÓPOLIS, 2014, p. 1).

Apesar de a formação em nível médio ser na área de Magistério, há a exigência de formação na área de Tradução e interpretação em Libras. Podemos ver o edital emergencial como um saldo otimista das legislações vigentes. Novos rumos estão sendo traçados na educação inclusiva no que diz respeito ao aluno Surdo e isso se reflete nas práticas tradutórias.

Como proposta para futuros editais, é necessário rever, problematizar e alterar as leis de cargos do magistério dos respectivos municípios. Além disso, considerar o momento histórico na composição de perfis profissionais. Nosso argumento final centra-se na inclusão das diretrizes sobre interpretação comunitária, aplicada ao contexto educacional, desdobrando-se em orientações e formação continuada, que qualifiquem o serviço de tradução e de interpretação Libras-Português. Como proposta final, fica a do reconhecimento do curso de Bacharelado em Letras-Libras, e que a formação do TILS em contextos educacionais de nível básico seja recomendada nos editais, possibilitando a formação continuada desses profissionais.

\begin{abstract}
In Brazil, a number of language policies around the Brazilian Sign Language were implemented with greater vigor from the Decree No. 5,626 / 05. Even with the advances of language policies, there are several challenges regarding the hiring of translators and sign language interpreters (TILs), mainly in the educational context. This research investigates the duties to be performed by professionals in the cities of Florianópolis and Itajaí, in the educational context of basic education. The corpus used in this study was restricted to public procurement notices published in the years 2005 to 2013. In the educational context, aspects such as learning processes of deaf pupils, confusion of roles between teaching and the translation exercise are facts that underlie the action these professionals. This research has aimed to observe, analyze and classify the attributes present in notices intended for TILs in the analyzed cities. The methodology used is the analysis of documents, literature of qualitative nature. The data show that the city of Itajaí has more translational nature of duties of the city of Florianopolis. Still found the need for guidelines on the translation exercise in the educational context, to support the precepts of community interpreting.
\end{abstract}

Key words: educational interpreter, Brazilian Sign Language/Portuguese, work tasks. 


\section{Resumen}

En Brasil se ha implementado una serie de políticas lingüísticas en torno a la Lengua Brasileña de Señales, con más vigor a partir del Decreto No. 5.626/05. A pesar de esos avances de las políticas lingüísticas, existen diversos retos en lo que concierne a la contratación de traductores e intérpretes de lengua de signos (en adelante, TILS), sobre todo en el contexto educativo. Esta investigación analiza las atribuciones a ser desempeñadas por esos profesionales en dos ciudades Florianópolis e Itajaí (BR), en el contexto educativo de la enseñanza básica. Para ello, el corpus utilizado en esta investigación se restringió a las oposiciones públicas, cuyas convocatorias se publicaron entre los años de 2005 y 2013. Quadros (2004) y Lacerda (2008) destacan que existen aspectos que se orientan más allá de la actuación de los TILS en el contexto educativo, tales como: los procesos de aprendizaje de los alumnos sordos y la confusión de papeles entre la docencia y el ejercicio de traducir. El propósito de esta investigación es observar, analizar y clasificar las atribuciones presentes en las convocatorias dirigidas a los TILS en las ciudades de análisis. La metodología adoptada posee base documental, bibliográfica y carácter cualitativo. Como resultados, los datos conducen a las siguientes afirmaciones: no se hicieron modificaciones en las atribuciones en el periodo analizado; Itajaí posee más atribuciones en el ámbito de la traducción, comparada a Florianópolis; y existe gran disparidad entre las atribuciones de las dos ciudades.

Palabras clave: intérprete educativo; Lengua Brasileña de Señales/Portugués; atribuciones de trabajo.

\section{Referências:}

ALBIR, Amparo Hurtado. O desenvolvimento da competência do tradutor: em busca de parâmetros cognitivos. In: ALVES, F; MAGALHAES, C; PAGANO, A. Competência em tradução: cognição e discurso. Belo Horizonte: UFMG, 2005.

BRASIL. Decreto $\mathrm{n}^{\circ} 5.626$, de 22 de dezembro de 2005. Regulamenta a Lei $\mathrm{n}^{\mathrm{o}} 10.436$, de 24 de abril de 2002, que dispõe sobre a Língua Brasileira de Sinais - Libras, e o art. 18 da Lei no 10.098, de 19 de dezembro de 2000. Diário Oficial [da] União, Brasília, DF, 23 dez. 2005. Disponível em: <http://www.planalto.gov.br/ccivil_03/_ato20042006/2005/decreto/d5626.htm>. Acesso em: 22 dez. 2014.

. Lei $\mathrm{n}^{\circ}$ 12.319/2010. Regulamenta a profissão de Tradutor e Intérprete da Língua Brasileira de Sinais - LIBRAS. Diário Oficial [da] União, Brasília, DF, 2 set. 2010. Disponível em: <http://www.planalto.gov.br/ccivil_03/_Ato2007-2010/2010/Lei/L12319.htm>. Acesso em: 24 mar. 2014.

BRASIL. Lei $\mathrm{n}^{\circ}$ 10.436, de 24 de abril de 2002. Dispõe sobre a Língua Brasileira de Sinais Libras e dá outras providências. Diário Oficial [da] União, Brasília, DF, 25 abr.2002. Disponível em: 〈http://www.planalto.gov.br/ccivil_03/leis/2002/L10436.htm>. Acesso em: 22 dez. 2014.

CAMARGO, Ana Claudia dos Santos; ALBRES, Neiva de Aquino. O conhecimento legítimo para intérprete educacional Inscrito em provas de concurso: a contratação de intérpretes no 
Brasil. In: Congresso Nacional de Pesquisas em Tradução e Interpretação em Libras e Língua Portuguesa, 3., Santa Catarina, 2012. Anais eletrônicos... Santa Catarina: Programa de PósGraduação em Estudos da Tradução da UFSC, 2012. Disponível em:

〈http://www.congressotils.com.br/anais/tils2012_politicasdetraducao_camargoalbres.pdf $>$. Acesso em: 11 dez. 2013.

COSTA, Andréia Santos da; EBLING, Priscila dos Santos; WITCHS, Pedro Henrique. As diferentes funções desempenhadas pelo intérprete educacional. In: Congresso Nacional de Pesquisas em Tradução e Interpretação em Libras e Língua Portuguesa, 3., Santa Catarina, 2012. Anais eletrônicos... Santa Catarina: Programa de Pós-Graduação em Estudos da Tradução da UFSC, 2012. Disponível em:

$<$ http://www.congressotils.com.br/anais/anais/tils2012_traducao_questao_witchseblingcosta.p df>. Acesso em: 10 dez. 2013.

DORZIAT, Ana; ARAUJO, Joelma Remígio de. O intérprete de língua de sinais no contexto da educação inclusiva: o pronunciado e o executado. Revista Brasileira de Educação

Especial, Marília, v. 18, n. 3, set. 2012. Disponível em:

$<$ http://www.scielo.br/scielo.php?script=sci_arttext\&pid=S141365382012000300004\&lng=pt\&nrm=isso $>$. Acesso em: 13 nov. 2013.

FLORIANÓPOLIS. Edital n 001/2009. Prefeitura de Florianópolis, 2009. Disponível em: 〈http://www.pmf.sc.gov.br/entidades/educa/index.php?cms=concurso+publico $>$. Acesso em: 25 mar. 2015.

FLORIANÓPOLIS. Edital nº 008/2010. Concurso Público para os cargos de Administrador Escolar, Auxiliar de Sala, Auxiliar de Ensino, Professor e Supervisor Escolar. Prefeitura de Florianópoli, 2010. Disponível em: <http://www.pmf.sc.gov.br/entidades/educa/index.php?cms=concurso+publico $>$. Acesso em: 25 mar. 2015

FLORIANÓPOLIS. Edital nº 003/2011. Concurso Público ao provimento dos cargos de Professor de LBRAS, Auxiliar de Ensino de LIBRAS, Auxiliar de Sala e Bibliotecário. Prefeitura de Florianópolis, 2011. Disponível em: <http://www.pmf.sc.gov.br/entidades/educa/index.php?cms=concurso+publico $>$. Acesso em: 25 mar. 2015.

FLORIANÓPOLIS. Edital de Concurso Público destinado ao provimento de cargos das categorias funcionais dos Grupos Docente e Especialistas em Assuntos Educacionais da Rede Municipal de Ensino de Florianópolis. Prefeitura Municipal de Florianópolis [Secretaria Municipal de Educação e Secretaria Municipal da Administração, Arquivo de concurso público, FEPESE/SC], 2014. Disponível em: 〈http://educa2014.fepese.org.br〉 . Acesso em março/2015.

ITAJAÍ. Secretaria Municipal de Educação. Edital n 004/2011. Destinado a prover vagas no nível inicial do Quadro Permanente de Pessoal da Secretaria Municipal de Educação, define suas normas e dá outras providências. Prefeitura de Itajaí, 2011. Disponível em: 
$<$ http://antigo.educacao.itajai.sc.gov.br/index.php?option=com docman\&task=doc do wnload\&gid=419\&Itemid=173> . Acesso em: 14 out. 2015.

ITAJAÍ. Secretaria Municipal de Educação. Edital nº 022/2013. Destinado a prover vagas no nível inicial do Quadro Permanente de Pessoal da Secretaria Municipal de Educação, define suas normas e dá outras providências. Prefeitura de Itajaí, 2013. Disponível em: <https://site.pciconcursos.com.br/arquivo/1229215.pdf>. Acesso em: 14 out. 2015.

LACERDA, Cristina Broglia. Tradutores e intérpretes de Língua Brasileira de Sinais: formação e atuação nos espaços educacionais inclusivos. Cadernos de Educação, Pelotas, n. 36, maio/ago. 2010. Disponível em:

<http://www2.ufpel.edu.br/fae/caduc/downloads/n36/06.pdf>. Acesso em: 11 dez. 2013.

MOURÃO, Carlos Antonio Fontenele, DIAS JÚNIOR, Jurandir Ferreira, CORDEIRO, Leane Pereira. O intérprete de língua de sinais na escola pública. 2012. In: Congresso Nacional de Pesquisas em Tradução e Interpretação em Libras e Língua Portuguesa, 3., Santa Catarina, 2012. Anais eletrônicos... Santa Catarina: Programa de Pós-Graduação em Estudos da Tradução da UFSC, 2012. Disponível em:

$<$ http://www.congressotils.com.br/anais/anais/tils2012 traducao_questao_mouraojrcordeiro.p df>. Acesso em: 12 dez. 2013.

PÖCHHACKER, Franz. Introducing interpreting studies. London and New York: Routlegde, 2004.

QUADROS, Ronice Müller de Quadros. O tradutor Intérprete de Língua de Sinais e Língua Portuguesa. Brasília: MEC; SEESP, 2003.

QUADROS, Ronice M. O tradutor e interprete de língua brasileira de sinais e língua portuguesa. Brasília: SEESP, 2004.

QUEIROZ, Mylene. Interpretação médica no Brasil. 134f. Dissertação (Mestrado em Estudos da Tradução) - Universidade Federal de Santa Catarina, Centro de Comunicação e Expressão, Programa de Pós-Graduação em Estudos da Tradução, Florianópolis, SC, 2011. Disponível em: < https://repositorio.ufsc.br/xmlui/handle/123456789/95825>. Acesso em: 22 dez. 2014.

RODRIGUES, Carlos Henrique. Da interpretação comunitária à interpretação de conferência: desafios para formação de intérpretes de língua de sinais. In: Congresso Nacional de Pesquisas em Tradução e Interpretação em Libras e Língua Portuguesa, 2., Santa Catarina, 2010. Anais eletrônicos... Santa Catarina: Programa de Pós-Graduação em Estudos da Tradução da UFSC, 2010. Disponível em:

〈http://www.congressotils.com.br/anais/anais2010/Carlos\%20Henrique\%20Rodrigues.pdf>. Acesso em: 23 mar. 2014.

SAMPIERI, Roberto Hernández; COLLADO, Carlos Hernández; LUCIO, Pilar Baptista. Metodologia de pesquisa. São Paulo: AMGH, 2006. 
SHUTTLEWORTH, Mark; COWIE, Moira. Dictionary of Translation Studies. UK: Stjerome Publishing. Manchester, 1997.

WADENSJÖ, Cecilia. Dialogue interpreting: A monologising practice in a dialogically organised world. Target, v. 16, n. 1, 200, p. 105-124. 